\title{
BRINCANDO NA EDUCAÇÃO INFANTIL: A LUDICIDADE NO DESENVOLVIMENTO DA CRIANÇA
}

Janaina Ricci; Maria Ruth da Silva Reis; Michele Dias Luccas; Leonardo de Angelo Orlandi; Carolline Rodrigues Guedes; José Milton de Lima; Márcia Regina Canhoto de Lima.

Curso de Educação Física - Departamento da Educação Física, Curso de Pedagogia - Departamento de Educação, Faculdade de Ciências e Tecnologias - UNESP campus de Presidente Prudente. E-mail: janaina-ricci@hotmail.com

\section{RESUMO}

O presente artigo expõe o projeto intitulado "Brincando na Educação Infantil: A ludicidade no desenvolvimento da criança", que tem como objeto de investigação e intervenção a criança e a ludicidade, respectivamente como recurso pedagógico privilegiado no contexto da Educação Infantil. Os referenciais teóricos fundamentam-se principalmente em autores da Sociologia da Infância e outros estudiosos acerca da temática. O objetivo do projeto foi inserir a ludicidade no meio escolar, como meio para o desenvolvimento da imaginação e das habilidades motoras e sociais das crianças, além de sensibilizar os educadores sobre a importância da ludicidade para o desenvolvimento harmonioso das crianças. A metodologia utilizada é a pesquisa-ação que sustenta a preocupação de transformação da realidade e a estreita relação entre teoria e prática. Verifica-se, gradativamente, por meio das intervenções, mudanças de concepção e de postura dos participantes no tratamento da ludicidade como atividade indispensável no contexto da Educação Infantil.

Palavras-chave: Criança; Ludicidade; Educação Infantil; Sociologia da Infância; Imaginação.

\section{INTRODUÇÃO E OBJETIVO}

Durante muito tempo, as crianças foram regidas e criadas pelos costumes dos adultos e vistas como tábulas rasas, seres passivos e incapazes de produzir cultura. No contexto educacional atual, esse pensamento não é muito diferente, uma vez que as crianças ainda não têm suas particularidades reconhecidas e respeitadas e continuam crescendo e aprendendo através de parâmetros que não estão em consonância a legislação e produção científica atual.

Diante dessa realidade, pesquisadores da área da Educação Infantil vêm tentando desvendar e quebrar tais concepções que denominam a criança como "semente de um jardim", "tabula rasa", "um vir a ser" ou um "adulto em miniatura", e defendem a ideia de que a criança é construída através do contexto social, histórico e cultural onde está inserida.

Outra visão que vem causando discussão entre os estudiosos é a de enxergar a criança como um ser dependente e incapaz. Na contramão dessas concepções adultocêntricas, a Sociologia da Infância considera as crianças não como receptoras passivas e reprodutoras, mas sim, sujeitos criativos e produtores de cultura. Constituem-se na capacidade de construção e de 
significação do mundo, independente da visão adulta, ela deve ser reconhecida como sujeito social e participante de sua socialização (SARMENTO 2004).

Com enfoque nessa abordagem, o presente trabalho, intitulado: "Brincando na Educação Infantil: A ludicidade no desenvolvimento da criança" tem como principal objeto de estudo a prática de atividades lúdicas e imaginativas, que visa inserir e estimular as brincadeiras e jogos dentro do contexto da Educação Infantil. Investe, também, para que os professores da instituição educacional parceira entendam a importância da ludicidade, e a empreguem no decorrer de suas práticas educativas.

O projeto, financiado pela PROEX - Pró-Reitoria de Extensão Universitária da UNESP, é realizado por docentes e discentes dos Cursos de Pedagogia e Educação Física, que fazem parte do Centro de Estudos e Pesquisa em Educação, Ludicidade, Infância e Juventude (CEPELIJ), inserido na Faculdade de Ciências e Tecnologia - UNESP, Campus de Presidente Prudente. Na sua realização, o projeto conta com a parceria de uma instituição municipal de Educação Infantil, localizada em um dos Distritos do Município de Presidente Prudente, interior do Estado de São Paulo.

Conforme ressaltado, este trabalho adota como referencial teórico a Sociologia da Infância, responsável por nortear os estudos das culturas da infância; da concepção de infância; de imaginação e brincadeira, e que traz contribuições significativas para a superação de práticas que não potencializam o desenvolvimento da criança no contexto da Educação Infantil.

Através de leituras referentes ao tema pesquisado, pode-se afirmar que trabalhar com a imaginação da criança, seus movimentos e relações sociais possibilita que ela desenvolva a imaginação, a motricidade, o pensamento, a atenção, a concentração, a memória, o domínio da vontade, e a interação social entre seus pares e com os adultos.

Sendo assim, o projeto trata da ludicidade no contexto escolar, e investe na formação de discentes, por meio de reuniões de estudos e vivências na realidade educacional, visando compreender a educação para a infância, e o papel da escola e dos professores no atendimento às exigências históricas atuais.

Diante do exposto acima, o principal objetivo do projeto baseia-se em introduzir e expandir a cultura lúdica dos alunos e professores da instituição parceira, e ampliar o repertório de brincadeiras das crianças, na expectativa de que elas as (re) signifiquem e reproduzam juntamente com os demais alunos, professores, pais, amigos e até mesmo sozinhas. Todo processo buscou conscientizar e dar suporte aos educadores para que estes pudessem respeitar valorizar as 
crianças e tornar o ambiente escolar mais prazeroso e significativo tanto para as crianças quanto para os próprios educadores.

\section{FUNDAMENTAÇÃO TEÓRICA}

A Sociologia da Infância é uma área de estudos específicos sobre criança e infância que considera a singularidade de cada criança conforme seu contexto e suas relações sociais. Autores como Corsaro, Sarmento, Müller, entre outros, têm contribuído para modificar as concepções antigas de que a criança seja apenas um "adulto em miniatura".

Os estudos da Sociologia da Infância focam na voz e no olhar da criança, considerando-a como construtora e produtora de cultura, vista como atores sociais que se relacionam com seus pares e com os adultos, família, escola, entre outros.

A partir desta interação, são construídas as culturas da infância:

Por esse conceito entende-se a capacidade das crianças de construírem de forma sistematizada modos de significação do mundo e de ação intencional, que são distintos dos modos adultos de significação e ação (SARMENTO, 2002, p. 3 e 4).

Sarmento (2002) destaca quatro eixos estruturadores das Culturas da Infância: interactividade, fantasia do real, ludicidade e reiteração.

$\mathrm{Na}$ interactividade a criança compartilha através da cultura de pares seus saberes e aprendizados, que contribuem para sua formação social e pessoal, como: família, amigos, escola, etc.

A fantasia do real revela-se no faz de conta, no jogo simbólico por meio dos quais a criança constrói sua visão de mundo e os significados do mundo natural e social. A imaginação é vista também como uma forma de superar contextos difíceis e até dolorosos, e também auxilia na criatividade e na aproximação com situações e personagens favoritos.

A reiteração refere-se à criança retomar, repetir, recriar e reinventar personagens e situações inéditas no decorrer da brincadeira, pois a criança tem um tempo recursivo que pode ser retomado, estendido e revivido.

A ludicidade tem uma estreita relação com a fantasia, segundo Sarmento (2002) o brincar não é exclusividade das crianças, mas é próprio do homem, sendo ainda uma das suas atividades sociais mais significativas. Diferentemente do adulto, o brincar é o que as crianças fazem de mais sério. 
É possível certificar que por meio da manifestação das Culturas da Infância, as crianças são agentes sociais ativos que desenvolvem, produzem e recriam cultura possuindo direitos e deveres que são assegurados por legislações.

As Diretrizes Curriculares Nacionais para a Educação Infantil (BRASIL, 2009) apresentam propostas pedagógicas que têm como objetivos, garantir à criança formas de apropriação, integração de conhecimentos e aprendizagem de várias linguagens, além de ter direito à liberdade, expressão, respeito, convivência e interação com as outras crianças.

Dessa forma, o artigo 4음 da DCNEF (BRASIL, 2009), relata que:

As propostas pedagógicas da Educação Infantil deverão considerar que a criança, centro de planejamento curricular, é sujeito histórico e de direitos que, nas interações, relações e práticas cotidianas que vivencia, constrói sua identidade pessoal e coletiva, brinca, imagina, fantasia, deseja, aprende, observa, experimenta, narra, questiona e constrói sentidos sobre a natureza e a sociedade, produzindo cultura.

A partir da citação acima, podemos concluir que as crianças não estão tendo seu devido reconhecimento perante a sociedade à respeito dos seus direitos, pois ela está sendo sujeita a inúmeras atividades, que muitas vezes, não contribuem è não respeitam o seu direito à infância.

Dallabona e Mendes (2004) rejeitam a ideia das atividades precoces para as crianças, pois, o jogo e a brincadeira têm um papel relevante na construção do pensamento, da socialização e desenvolvimento infantil, de maneira global. Brincando e jogando a criança reproduz diversas situações vividas em seu cotidiano, tanto pela imaginação quanto pelo faz de conta. O brinquedo faz parte da vida da criança e tem como principal função estimular a brincadeira, favorecendo os momentos de alegria, diversão e facilitando o exercício das diversas habilidades e capacidades das crianças.

É necessário que o educador insira o brincar em um projeto educativo, o que supõe intencionalidade, ou seja, ter objetivos e consciência da importância de sua ação em relação ao desenvolvimento e à aprendizagem (FORTUNA, 2004, página 6).

Nessa perspectiva, os educadores têm o papel fundamental de compreender a realidade das crianças e propiciar atividades lúdicas, levando em consideração os interesses e as necessidades das crianças. É preciso reconhecer as implicações da atividade lúdica como meio para o desenvolvimento da criança.

Uma escola que integra o brincar ao processo de ensino aprendizagem, está preocupada com a formação de todo o homem, ou seja, sua 
objetividade, sua autonomia, sua criatividade, suas funções sociais, o exercício da cidadania e a atuação na sociedade na qual está inserido (AYRES; SENA, 2010, p.111).

Apesar de existirem concepções e legislações que defendem os direitos da criança em relação à brincadeira, são notáveis situações contraditórias no contexto da Educação Infantil. Isso se deve pela falta de tempo destinado à ludicidade na escola, pelo fato dos professores sobrecarregarem as crianças com preocupações e conteúdos que visam à preparação para o futuro, e as particularidades das crianças vão sendo cada vez menos reconhecidas e respeitadas.

\section{METODOLOGIA}

A metodologia adotada para o desenvolvimento do projeto é a Pesquisa-ação, que almeja transformações na realidade, pautadas no estudo, na reflexão e no comprometimento de todos os integrantes do projeto. Essa investigação está devidamente aprovada no Comitê de Ética da FCT/UNESP com o protocolo do processo sob o n 1/2011.

Todos os problemas que são observados e destacados durante o processo, são expostos na tentativa de resoluções embasadas no conhecimento teórico e nas experiências alcançadas, considerando o histórico e a capacidade dos participantes. Neste contexto, o grupo conta com a disponibilidade e comprometimento de todos: coordenadores, discentes, professores e crianças da instituição parceira.

Utilizamos como procedimentos metodológicos, o diário de campo, onde são anotados os dados que mais nos chamam atenção e fotografias das crianças. As intervenções são realizadas semanalmente com crianças de quatro e cinco anos juntamente com a participação dos professores.

Para a avaliação do andamento e dos resultados do projeto, foram elaboradas questões para que os professores descrevessem o que, e como está sendo a relação da equipe com as crianças, e qual a sua opinião sobre a relevância do projeto no contexto investigado.

Os discentes universitários que participam dessa pesquisa reúnem-se semanalmente para discutir e avaliar seus embasamentos teóricos e práticos, além de preparar o plano de aula e os conteúdos que são aplicados na semana seguinte na instituição. Quinzenalmente o grupo se reúne para aprofundamento teórico-metodológico no Grupo de Pesquisa: “Cultura Corporal: Saberes e Fazeres, inserido na FCT/UNESP. 


\section{RESULTADOS E DISCUSSÕES}

Através das intervenções, foi possível observar uma evolução gradativa na visão dos professores, em relação à importância da ludicidade, e o aumento no repertório de brincadeiras e imaginação das crianças, contribuindo satisfatoriamente com a ampliação de sua cultura lúdica, e o desenvolvimento motor e social das mesmas.

Em uma aula foi contada a estória do Lipe (amigo imaginário criado pelas crianças), nesta estória o personagem viajou com seu foguete para o espaço, com todas as roupas e acessórios espaciais. As crianças ficaram sentadas em suas carteiras, que eram seus foguetes imaginários, e durante a viagem, as crianças falavam umas com as outras o que viam no percurso:

Mateus (nome fictício): "Nossa eu to vendo um lobo na lua". Andressa (nome fictício): "Eu vi um mosquito, e era da dengue".

Outro aluno pegou seu telefone imaginário e disse: "Oi mãe, eu tô indo viajar pro espaço ta? Tchau".

E quando eles saíram do foguete outro aluno disse: "Eu tenho asas de fogo, pra viajar aqui".

Em outra intervenção, Lipe foi passear no zoológico com seu pai, e para a contextualização das crianças na estória, foram entregues máscaras de alguns animais: leão, macaco e elefante. Durante a estória, as crianças reproduziam os sons dos animais e dois alunos conversavam:

José (nome fictício): "Eu vou te pegar, eu sou um leão"

Pedro (nome fictício): "Não, você é um tigre".

Durante a pesquisa houve algumas falas das professoras em relação ao projeto, e foi relatado que:

Professora Maria (nome fictício): "As atividades envolvem movimento, coordenação, imaginação, criatividade, regras enfim tudo o que é necessário em benefício das crianças. Também ajudam em sala de aula no momento que exige concentração e realização das atividades. Vejo como positivo ainda pedirem a opinião dos alunos sobre o que gostariam de brincar e a participação de todos os alunos".

Professora Denise (nome fictício): "As aulas estão muito bem planejadas e organizadas, trazendo o máximo de alegria e satisfação. Seu desenvolvimento abrange a imaginação, uma melhor forma de se desenvolver e organizar. Aguça a imaginação através de histórias contadas que, em outro momento solicito que relembrem e contem para mim".

A partir dos resultados e das falas apresentadas, foi possível notar que as crianças desenvolveram-se bastante em relação à imaginação e à ludicidade. As falas da professoras 
consideram a pesquisa bastante significativa, pois constaram avanços na comunicação, na expressão, nas relações sociais e no aumento de interesse em relação à frequência à escola.

\section{CONCLUSÃO}

Apoiados na Sociologia da Infância e de autores relacionados a essa vertente, podemos considerar que o emprego da ludicidade como meio pedagógico faz com que as crianças alcancem um avanço significativo em relação a tempos passados, quando não se tinha por prática, o repertório de brincadeiras e fantasias. Percebemos melhorias nas interações sociais, nos aspectos cognitivos e motores, assim como o aumento da criatividade e participação nas atividades propostas.

Aos poucos os professores estão se conscientizando sobre a importância da ludicidade para o desenvolvimento das crianças, e os pontos positivos que essa prática traz como: maior atenção dentro da sala de aula, comportamento social menos conflituoso e seu desenvolvimento por completo.

O referido projeto foi proposto para ser realizado por um longo período, tanto que já está na instituição há mais de cinco anos, tendo alcançado resultados progressivos e sólidos. A escola, por não apresentar tanta rotatividade no corpo docente, possibilita investimentos e resultados coerentes com a metodologia adotada. Um último fator a ser destacado refere-se ao empenho da equipe de gestão da escola com a continuidade do trabalho, pois, além de acreditar no projeto, reflete compromisso com a comunidade e com o processo de formação das crianças, criando condições necessárias para uma estreita relação entre universidade e escola pública e teoria e prática.

\section{REFERÊNCIAS}

AYRES, J. S.; SENA, S.S. A importância do lúdico na Educação Infantil: fundamentação teórica. Caderno Multidisciplinar de Pós - Graduação da UCP. Pitanga, n.1, v.1, p. 106-121, jan.2010.

BRASIL, Ministério da Educação. Diretrizes Curriculares Nacionais para a Educação Infantil. Resolução CNE/CEB 5/2009. Brasília: Diário Oficial da União, dez. 2009.

DALLABONA, S. R.; MENDES, S. M. S. O lúdico na educação infantil: jogar, brincar, uma forma de educar. Revista de divulgação técnico-científica do ICPG. V. 1, n. 4, p. 1-12, jan/mar 2004.

FORTUNA, T. R. Faz de conta na escola: a importância do brincar. Revista Pátio Educação Infantildezembro de 2003 a março de 2004, edição 3 n. 1. 
SARMENTO, M. J. As culturas da infância nas encruzilhadas da 2a modernidade. Braga, Portugal. Universidade do Minho. Centro de Estudos da Criança (mimeo), 2002.

SARMENTO, M. J.; CERISARA, A. B. Crianças e Miúdos: perspectivas sociopedagógicas da infância e educação. Lisboa: Asa Editora S.A. 2004. 